\title{
In Search of the Effects of Competition on Unemployment: Evidence from OECD Countries
}

\author{
Bo Zhao \\ School of International Trade and Economics, University of International Business and Economics, Beijing, China. \\ E-mail: todd_zb@hotmail.com \\ Received September $13^{\text {th }}, 2011$; revised October $18^{\text {th }}, 2011$; accepted November $15^{\text {th }}, 2011$.
}

\begin{abstract}
This paper explores the empirical relationship between unemployment rate and product market competition in eighteen OECD countries through three sets of quantitative analyses. We find that the effect of competition on employment depends on the existing competition intensity and the relationship between the unemployment and competition appears to be inverted-N shape - in countries where existing competition intensity is either high or low, an increase in competition tends to reduce unemployment rate significantly; but for countries where existing competition intensity is moderate, intensified competition is more likely to increase unemployment rate significantly.
\end{abstract}

Keywords: Competition, Unemployment, Panel Data, SVAR

\section{Introduction}

Recent report from the International Labor Organization indicates that global unemployment rate in 2009 soared to an unprecedented height of approximately $6.6 \%$. Especially, the unemployment rates in the Developed Economies and European Union region jumped to $8.4 \%$. Moreover, the overall unemployment rates in the next ten years are expected to keep increasing [1]. Against such a background, the importance of understanding the factors that influence a country's unemployment cannot be overstated. Labor market institutions and distortions are arguably among the most significant factors. However, as observed and argued by many economists, the labor market institutions and distortions cannot fully explain the high unemployment rates (see Nickell et al. [2] for example).

More attention, therefore, has been directed at the product market imperfections and distortions, especially product market power, as a possible reason for the increasing unemployment rates. However, theoretical analyses suggest that the relationship between competition and unemployment may be ambiguous. Hence, it is necessary to examine the empirical evidence on this relationship. As far as we know, however, there is surprisingly little empirical work on this subject. Therefore, the main objective of this paper is to search for the effects of product market competition on unemployment by using data from eighteen OECD countries.

The rest of this chapter is organized as follows. Sec- tion 2 gives the list of estimation variables and discusses the measures of competition. In section 3, quantitative analyses are conducted to explore the relationship between unemployment and competition. Main conclusions are summarized in section 4 .

\section{Variables, Database and Proxies}

Our data sample mainly spans over 1970-2005 and crosses eighteen OECD countries: Australia, Austria, Belgium, Canada, Denmark, Finland, France, Greece, Ireland, Japan, Italy, Luxembourg, Netherlands, New Zealand, Norway, Sweden, the United Kingdom and the United States of America.

A complete list of variables and their proxies used in our estimations is provided in Table 1. Specifically, product market competition is a non-monetary concept which makes it hard to measure. The Herfindahl Index $(H H I)$ and the Price Cost Margin (PCM) are the two theoretical measures that are often used to identify the degree of competition in the product market. In this paper, we use $P C M$ to measure the degree of competition because of two advantages that it has over $H H I$ : 1) PCM can be approximated by using the macro level data; and 2) PCM can capture the competitions in both domestic and foreign markets.

Although the robustness of PCM as a measure of competition intensity has been questioned by many economists, there is no other practical measure for competition intensity, especially at the macro level [3]. 
Table 1. Variables and proxies.

\begin{aligned} \hline $\boldsymbol{u} & \begin{array}{l}\text { unemployment rate: ratio of unemployed to economically active } \\ \text { population }\end{array} \\$\hline $\boldsymbol{r} &$ interest rate: nominal annual interest rate \\ $\boldsymbol{N} &$ total labor force: economically active population \\ $\boldsymbol{s} &$ technical progress: productivity index \\ $\boldsymbol{p} &$ price level: consumer price index \\ $\boldsymbol{w} &$ labor compensation: total labor compensation divided by total \\ $\mathbf{C O M} &$ degree of product market competition: price cost margin \end{aligned}

Using the macro data sets, the aggregate $P C M$ can be calculated via:

$$
P C M=\frac{G O S-C F C-(T-S)}{G V A}
$$

where GVA is the Gross Value Added, GOS is the Gross Operating Surplus, $C F C$ is the Consumption of Fixed Capital, and $(T-S)$ is the Taxes Less Subsidies on products.

Let $C O M \equiv 1-P C M$ be the proxy for the degree of competition. Hence, a larger value of COM represents a more intensive competition product market.

\section{Regressions}

\subsection{Panel-Data Regression with Lagged Variables}

Trying to find the general effect of competition on unemployment, we start with a panel-data (time-series crosssection) regression. Due to the observed stickiness of unemployment and its delayed response to changes in economic variables, we use a model with lagged independent variables (i.e. a dynamic process) to describe and explain the unemployment rate. Moreover, since there are omitted variables, e.g. union density and education, which probably have different gross effects across countries, we use a country-specific intercept to capture these effects.

$$
\begin{aligned}
u_{i, t}= & \alpha_{i}+\sum_{k=0}^{Q} \beta_{k} \cdot \mathrm{x}_{i, t-k}+\varepsilon_{i, t} \\
& \text { with } i=1,2,3, \cdots, 18 \\
& \text { and } t=1972,1973, \cdots, 2005
\end{aligned}
$$

where $u_{i, t}$ is the observed unemployment rate at time $t$ for country $i, \mathrm{x}_{i, t}$ is the observations for a vector of the explanatory variables $(p, w, s, r, N, \mathrm{Com}), \beta_{k}$ is the slope coefficient vector of $k^{\text {th }}$ lagged independent variables, and $\alpha_{i}$ is the cross-section fixed effect (country-specific constant). Let $Q=1$, that is, one-period lag is applied.

To see more clearly the impact of competition on unemployment, we conduct two regressions: the first one excludes the variable COM, while in the second regres- sion, we add it in. Table 2 displays the regression results with PCSE estimators.

It is interesting to find that product market competition is indeed significantly related to the unemployment rates, and the overall effect of competition on unemployment appears to be positive. However, as noted, when COM is added into the regression, some statistic measures of regression are reduced. How could this happen? One possible reason is that the responses of the unemployment rates to the changes in competition are more complex, probably country-specific.

\subsection{A Structural VAR Approach}

The Structural Vector Autoregression (SVAR) is commonly used for estimating and forecasting systems of interrelated time series and for analyzing the dynamic impact of random disturbances on a system of variables, and it sidesteps the need for structural modeling by treating every endogenous variable in the system as a function of the lagged values of all of the endogenous variables in the system. In comparison with the paneldata analysis in Section 3.1, a SVAR model allows us to search and characterize the country-specific long-run effect of competition on unemployment rate.

The identifying assumptions used in our model can be summarized in the following contemporaneous relationship:

\begin{tabular}{|c|c|c|c|c|}
\hline Explanatory Variable & $\# 1$ & & $\# 2$ & \\
\hline$p_{t}$ & -0.359156 & * & -0.362129 & * \\
\hline$p_{t-1}$ & 0.396755 & * & 0.401480 & * \\
\hline $\log \left(w_{t}\right)$ & -14.01174 & $*$ & -13.01221 & * \\
\hline $\log \left(w_{t-1}\right)$ & 16.35585 & $*$ & 15.26283 & * \\
\hline$s_{t}$ & 0.023938 & ** & -0.004423 & \\
\hline$s_{t-1}$ & -0.078136 & * & -0.048781 & * \\
\hline$r_{t}$ & 0.055446 & * & 0.046219 & * \\
\hline$r_{t-1}$ & 0.222642 & * & 0.229598 & * \\
\hline $\log \left(N_{t}\right)$ & -20.19961 & * & -18.90145 & * \\
\hline $\log \left(N_{t-1}\right)$ & 10.65544 & * & 9.560489 & * \\
\hline$C O M_{t}$ & & & -2.220691 & * \\
\hline$C O M_{t-1}$ & & & 4.355663 & \\
\hline
\end{tabular}

$\left[\begin{array}{c}\varepsilon_{s} \\ \varepsilon_{N} \\ \varepsilon_{r} \\ \varepsilon_{p} \\ \varepsilon_{w} \\ \varepsilon_{C O M} \\ \varepsilon_{u}\end{array}\right]=\left[\begin{array}{ccccccc}g_{11} & 0 & 0 & 0 & 0 & 0 & 0 \\ 0 & g_{22} & 0 & 0 & 0 & 0 & 0 \\ 0 & 0 & g_{33} & 0 & 0 & 0 & 0 \\ g_{41} & g_{42} & g_{43} & g_{44} & g_{45} & g_{46} & 0 \\ g_{51} & g_{52} & g_{53} & 0 & g_{55} & 0 & 0 \\ g_{61} & g_{62} & g_{63} & 0 & g_{65} & g_{66} & 0 \\ g_{71} & g_{72} & g_{73} & g_{74} & g_{75} & g_{76} & g_{77}\end{array}\right]\left[\begin{array}{c}v_{s} \\ v_{N} \\ v_{r} \\ v_{p} \\ v_{w} \\ v_{C O M} \\ v_{u}\end{array}\right]$

Table 2. Panel-data regression results. 


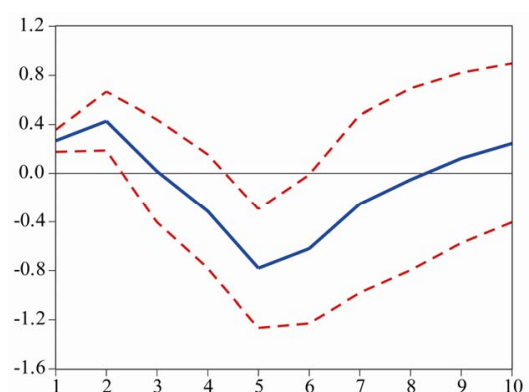

(a) Australia

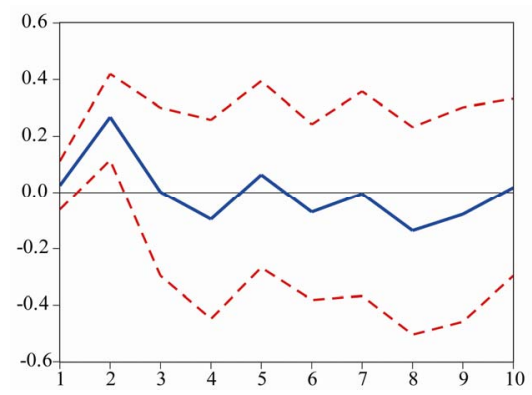

(d) Canada

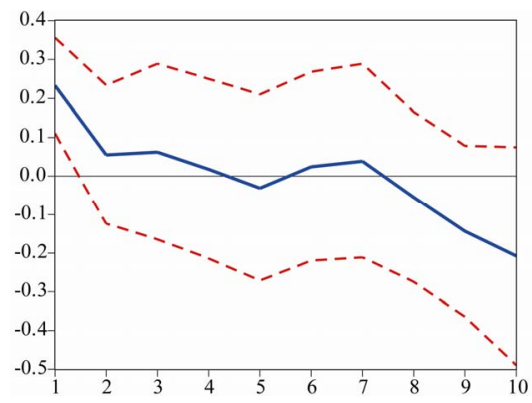

(g) France

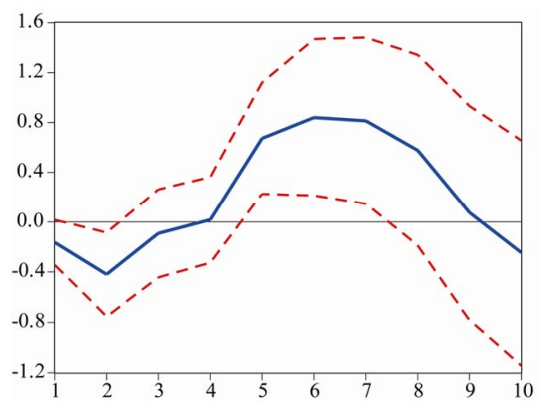

(j) Italy

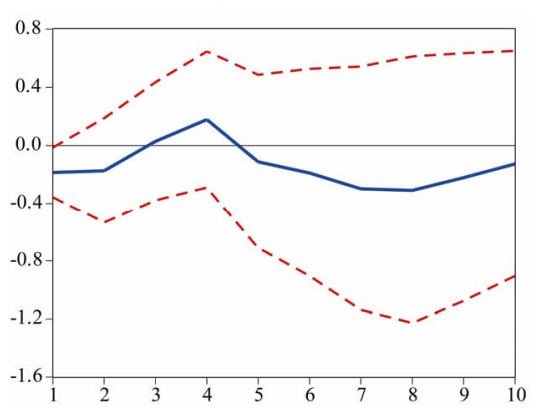

(m) Netherland

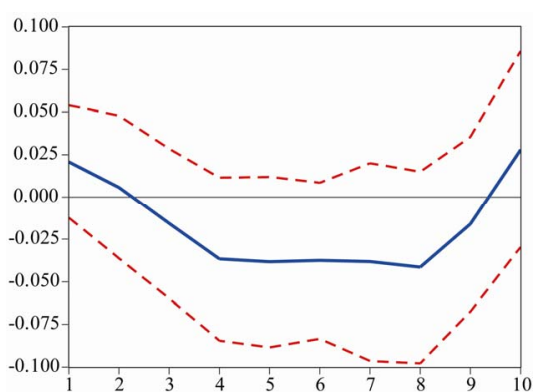

(b) Austria

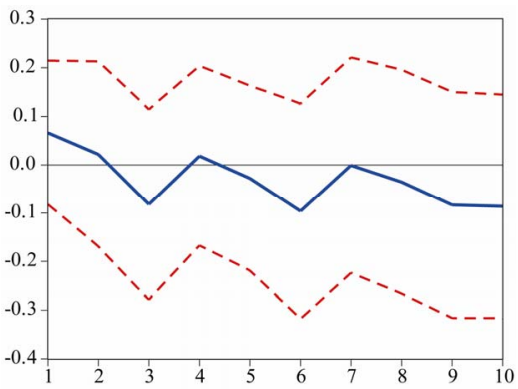

(e) Denmark

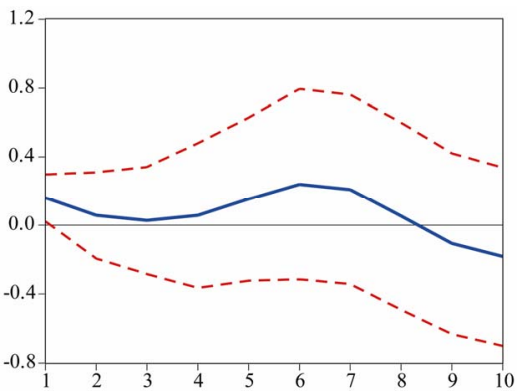

(h) Greece

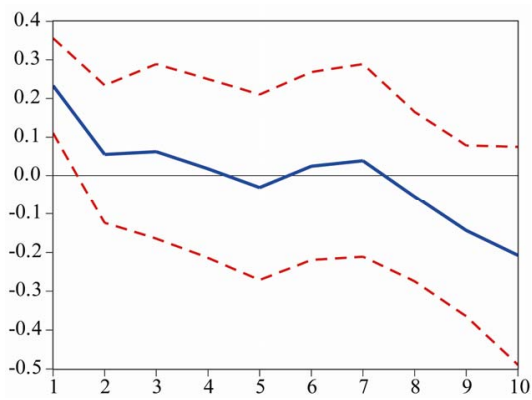

(k) Japan

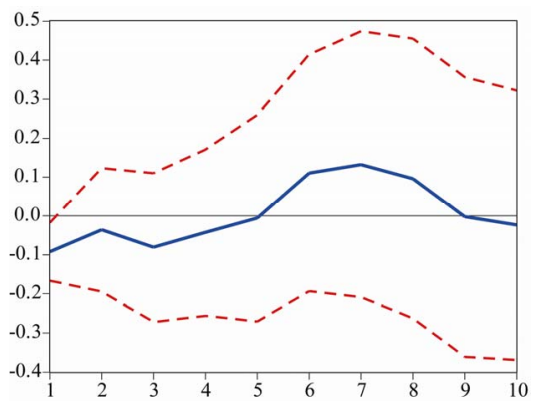

(n) New Zealand

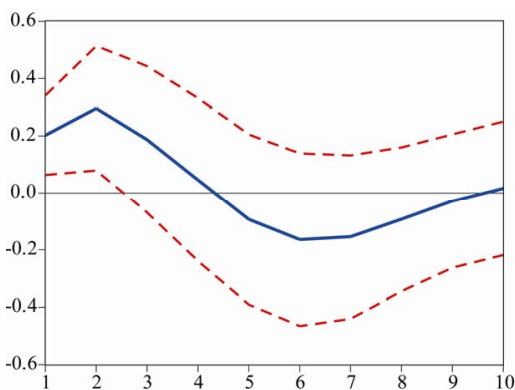

(c) Belgium

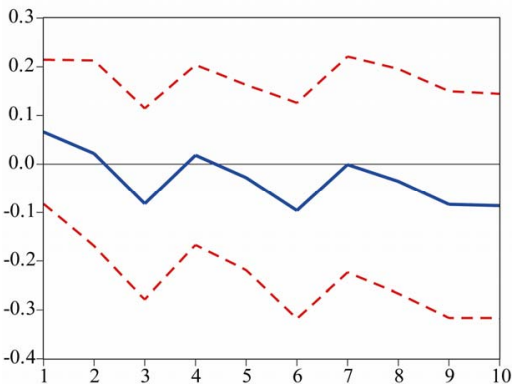

(f) Finland

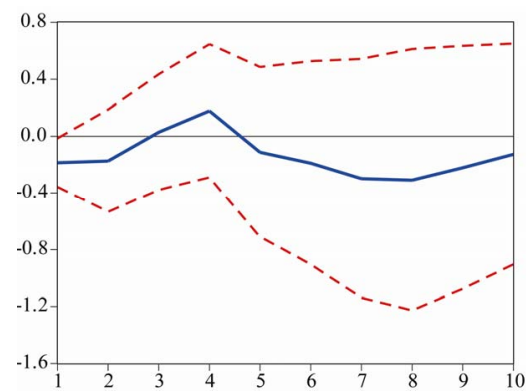

(i) Ireland

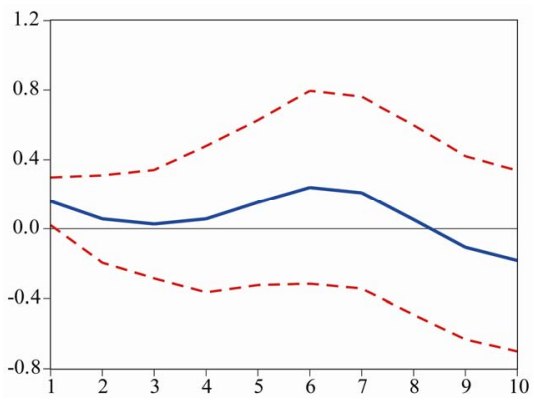

(1) Luxembourg

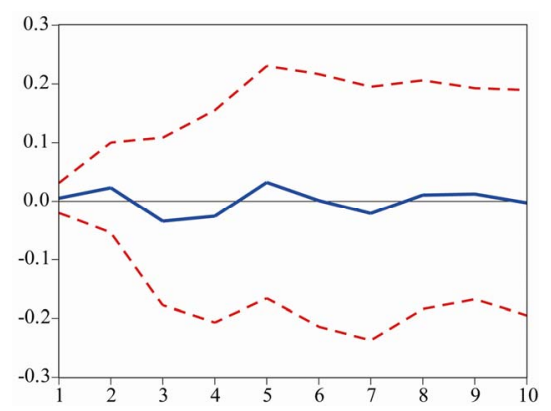

(o) Norway 


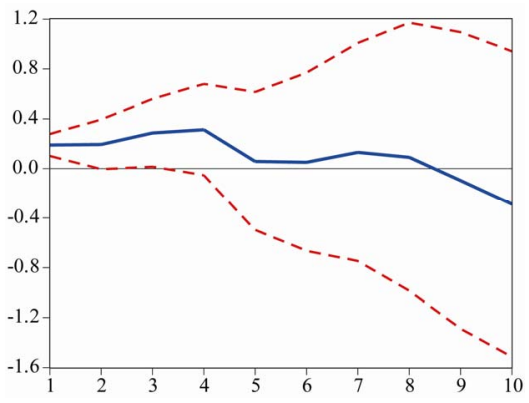

(p) Sweden

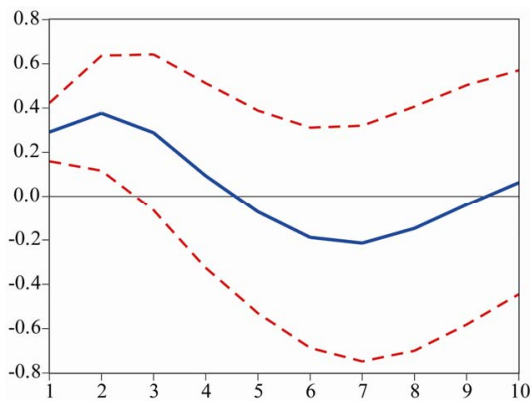

(q) UK

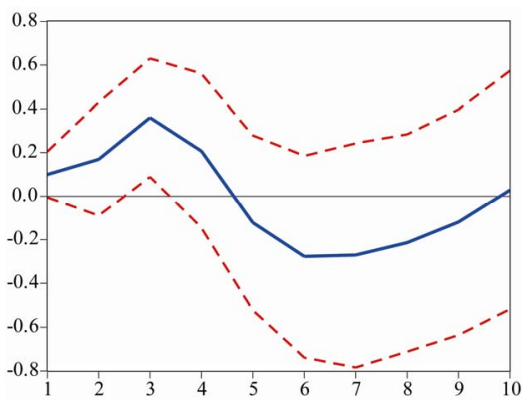

(r) USA

Figure 1. Structural impulse response of unemployment to a positive shock of competition.

where $\varepsilon$ is the structural disturbance, and $v$ is the residuals in the reduced form equations, representing unexpected movements of each variable.

Figure 1 shows the structural impulse responses (over ten years) of the unemployment rates to a one-time onestandard-deviation positive shock of product market competition for each country. The solid curve shows the percentage deviations from an underlying growth path, and the dashed curves plotted in each graph are one-standard-error bands. These diagrams demonstrate that the effect of competition on unemployment rate is significantly distinct across countries, both directionally and quantitatively.

\subsection{Grouped Panel-Data Analysis}

According to their specific response of unemployment to competition, the eighteen countries can be classified into two groups, as displayed in Table 3. Then we conduct a panel-data regression for each group. Just as expected, for those countries in Group A, intensified competition increases unemployment significantly; while for the countries in Group B, there is an opposite effect.

Moreover, we find that the average competition intensity of Group A is higher than that of Group B over 1970-2005. Therefore, the relationship between unemployment and competition seems to be U-shaped, as illustrated in Figure 2.

However, a closer examination of the ranking of competition intensity across countries suggests that the relationship between unemployment and competition may be more complex. As displayed in Table 4, most countries in Group A have an intermediate intensity of competition,

Table 3. Grouping by impulse response.

\begin{tabular}{rlc}
\hline Group & \multicolumn{1}{c}{ Countries } & Common Character \\
\hline A $\quad \begin{array}{l}\text { Australia, Belgium, Canada France, } \\
\text { Greece, Japan New Zealand, Sweden, } \\
\text { UK, USA }\end{array}$ & $\uparrow C O M \rightarrow u \uparrow$ \\
B & $\begin{array}{l}\text { Austria, Denmark, Finland Ireland, Italy, } \\
\text { Luxembourg Netherlands, Norway }\end{array}$ & 个 COM $\rightarrow u \downarrow$ \\
\hline
\end{tabular}

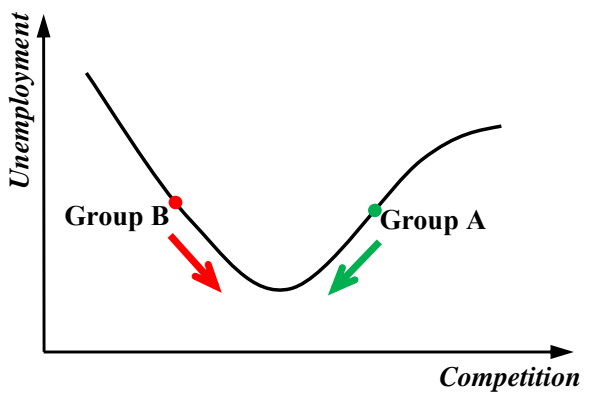

Figure 2. U-shaped relation between competition and unemployment.

Table 4. Average intensity of competition.

\begin{tabular}{cccc}
\hline Country & Group & Average Intensity of Competition ( $\uparrow$ ) \\
\hline Greece & A & 0.509174357 & \\
Luxemburg & B & 0.735863454 & D \\
Italy & B & 0.738866699 & \\
Ireland & B & 0.756146347 & 0.772045048 \\
Japan & A & 0.777843656 \\
New Zealand & A & 0.827443469 \\
Canada & A & 0.836445117 \\
USA & A & 0.841354966 \\
Netherlands & B & 0.843551061 \\
Australia & A & 0.849021465 \\
Belgium & A & 0.857324047 \\
Norway & B & 0.871354498 \\
France & A & 0.884357567 \\
Austria & B & 0.90062676 \\
Finland & B & 0.900998865 \\
UK & A & 0.921480577 \\
Sweden & A & 0.947884889 \\
Denmark & B &
\end{tabular}


Table 5. Grouped panel-data regression results (Grouped by Impulse Response).

\begin{tabular}{|c|c|c|c|c|}
\hline \multirow{2}{*}{$\frac{\text { Explanatory Variable }}{p_{t}}$} & \multicolumn{2}{|c|}{ Group C } & \multicolumn{2}{|c|}{ Group D } \\
\hline & -0.164559 & * & -0.406813 & $*$ \\
\hline$p_{t-1}$ & 0.148068 & * & 0.426115 & $*$ \\
\hline $\log \left(w_{t}\right)$ & -5.510587 & $*$ & -13.53308 & * \\
\hline $\log \left(w_{t-1}\right)$ & 11.59782 & * & 15.24213 & $*$ \\
\hline$s_{t}$ & -0.110827 & * & 0.024911 & \\
\hline$s_{t-1}$ & 0.022537 & & -0.076128 & ** \\
\hline$r_{t}$ & -0.128123 & * & 0.062993 & \\
\hline$r_{t-1}$ & 0.110894 & * & 0.168190 & $*$ \\
\hline $\log \left(N_{t}\right)$ & -36.76861 & * & 3.007705 & \\
\hline $\log \left(N_{t-1}\right)$ & 25.85197 & * & 3.727524 & \\
\hline$C O M_{t}$ & 0.451076 & & -3.155832 & * \\
\hline$C O M_{t-1}$ & 8.816740 & * & -1.221837 & \\
\hline
\end{tabular}

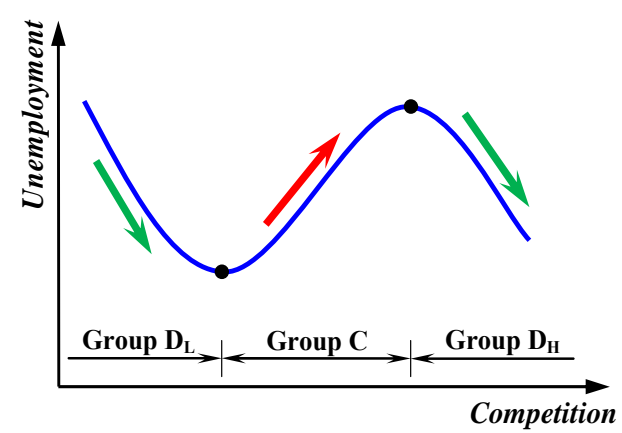

Figure 3. Inverted-N shaped relation between unemployment and competition.

while most countries in Group B have either the lowest or the highest competition intensity. This finding suggests that our conjecture - a U-shaped relation between unemployment and competition - is not accurate.

In light of Table 4, we regroup those eighteen countries according to the intensity of competition: one group (C) is composed of the nine countries that have an intermediate intensity of competition; another group (D) includes the four countries that have the lowest competition intensity and the five countries with the highest in- tensity of competition.

Table 5 reports the estimation results for these two groups. This regression result shows that for those countries where competition intensity is medium (i.e. Group C), increasing product market competition increases the unemployment rates more likely; while for those countries whose competition intensity at either the high or the low end (i.e. Group D), intensified competition in product market tends to reduce the unemployment rates.

This finding implies that the effect of competition on unemployment depends on the existing competition intensity and the relation between unemployment and the intensity of competition, as illustrated in Figure 3, is more likely to be inverted- $N$ shaped.

\section{Conclusions}

This paper, by using the macro data from eighteen OE$\mathrm{CD}$ countries, we have examined the relationship between product market competition and unemployment. Our analysis suggests that the relationship between these two variables is not simply monotonic. Rather, it appears to be inverted- $N$ shaped, with the effect of product market competition on unemployment depending on the existing competition intensity. Specifically, in countries where existing competition intensity is either high or low, increased competition in the product market tends to reduce unemployment significantly, but for countries where existing competition is moderate, intensified competition more likely increases unemployment. Therefore, our findings do not support the common belief among many economists that increased competition in the product market always improves the level of employment.

\section{REFERENCES}

[1] "Global Employment Trends," International Labor Organization, January 2010.

[2] S. Nickell, L. Nunziata and W. Ochel, "Unemployment in the OECD Since the 1960s. What Do We Know?" Economic Journal, Vol. 115, 2005, pp. 1-27. doi:10.1111/j.1468-0297.2004.00958.x

[3] J. Boone, "Competition," CEPR Discussion Papers, No. 2636,2000 . 